\title{
Cytogenetics of bisexual/unisexual species of Poecilia. IV. Sex chromosomes, sex chromatin composition and Ag-NOR polymorphisms in Poecilia latipinna: a population from Mexico
}

\author{
LUCIANA SOLA, SIMONA BRESSANELLO, ELLEN M. RASCH* \& PAUL J. MONACO* \\ Dipartimento di Biologia Animale e dell'Uomo, Università di Roma 'La Sapienza', via A. Borelli 50, 00161 Roma, Italy \\ and *Department of Biophysics, East Tennessee State University, Johnson City, TN 37614, U.S.A.
}

\begin{abstract}
Cytogenetic analysis using C-banding, silver staining and fluorescent staining was carried out on a population sample of Poecilia latipinna derived from Tampico, Mexico, to verify the presence of sex chromosomes in individuals from the southern areas of this species range and to investigate the extent of $\mathrm{C}$-band and $\mathrm{Ag}-\mathrm{NOR}$ polymorphisms. Females were found to have $\mathrm{W}$ heteromorphic chromosomes, with large amounts of heterochromatin-rich in AT nucleotide sequences. C-banding corresponded to the pattern proposed as typical for the genus. Specimens share one of the AgNOR locations previously described in populations from the U.S.A. and show additional ones as well.
\end{abstract}

Keywords: fish, NOR polymorphism, Poecilia latipinna, Poeciliidae, sex chromatin, sex chromosomes.

\section{Introduction}

Previous observations on three populations of Poecilia latipinna from northern areas of the species range (Texas and Florida, U.S.A.) have shown the existence of sex chromosomes of the $\mathrm{ZW}(\% ᄋ) / \mathrm{ZZ}\left(0^{*} \sigma^{*}\right)$ type (Sola et al., 1990). Sex determining mechanisms in the genus Poecilia are variable. For example, both male and female heterogametic species, with different degrees of sex chromosome differentiation, coexist with species having no obvious sex chromosomes (for review see Sola et al., 1992a,b); moreover, in other poeciliid species polymorphic sex-determining mechanisms exist (Kallman, 1984). These facts led us to analyse a fourth population sample of $P$. latipinna from Tampico, Mexico, a region that is near the southern limit of this species range (Miller, 1983). We wanted to verify the presence of sex chromosomes in specimens from widely disparate regions. Analysis of a Tampico population of $P$. latipinna is also of interest because in this area these fish are sympatric with the

Correspondence: Dr Luciana Sola, Dipartimento di Biologia Animale e dell'Uomo, via A. Borelli 50, 00161 Roma, Italy. unisexual species, $P$. formosa, and the sexual species, $P$. mexicana. Together, these three species constitute a breeding complex in which triploid unisexuals are produced (Balsano et al., 1989). Note that in the latter species chromosomes similar to the $\mathrm{W}$ chromosome of $P$. latipinna have not been found (Sola et al., 1992a, b).

In the three U.S.A. populations of $P$. latipinna previously analysed (Sola et al., 1990), the W chromosome is characterized by a large amount of heterochromatin. Our aim in the present manuscript is to report on our analysis of sex chromatin using AT- and GC-specific fluorochromes. In addition, chromosomes from the three U.S.A. populations show polymorphic C-bands and a high level of $\mathrm{Ag}$-NOR variability. We wanted to see if this variability persists in other populations of $P$. latipinna as well.

\section{Materials and methods}

The specimens analysed were laboratory-reared in Rome but were derivatives from specimens collected in the Laguna de la Puerta, Altamira, near Tampico, Mexico, in June 1988. Somatic metaphases were prepared from spleen, gill and cephalic kidney cells (Hitotsumachi et al., 1969). NORs were silver (Ag) stained by 
the method of Howell \& Black (1980) and C-banding was done according to Sumner (1972). Fluorescent staining with DAPI, quinacrine and chromomycin $\mathrm{A}_{3}$ $\left(\mathrm{CMA}_{3}\right)$ was carried out as described in Sola et al. (1992b) on slides made from the Tampico specimens and on slides made from the three U.S.A. populations (Sola et al., 1990).

\section{Results}

Cytogenetic observations from five specimens of $P$. latipinna collected near Tampico are summarized in Table 1.

Giemsa-stained metaphases from female specimens show a slightly heteromorphic chromosome, that for its size can be considered a homologue of pair number 2 (Fig. 1a). After C-banding, metaphases from male (Fig. 1b) or female (Fig. 1c) specimens are clearly distinguishable because of the large amount of heterochromatin on the $\mathrm{W}$ chromosome (Fig. $1 \mathrm{c}$ and $2 \mathrm{c}$ ). In both male and female specimens, one pair of small chromosomes shows telomeric heterochromatin (Fig. $1 \mathrm{~b}$ and $\mathrm{c})$. In specimens from all populations, hetero- chromatic regions of the $\mathrm{W}$ chromosome appear brightly fluorescent following DAPI-staining both in previously C-banded (Fig. 2a and d) and untreated (Fig. 2b and e) metaphases. The telomeric heterochromatin of the small size chromosomes, on the other end, appears to be bright only in previously C-banded metaphases (Fig. 2a). Quinacrine and DAPI on untreated slides produce a similar pattern: uniform staining of euchromatin and heterochromatin in the chromosome complement with the exception of the terminal region of the $\mathrm{W}$ chromosome (Fig. $2 \mathrm{~b}$ and e). An AT-rich nature of the $\mathrm{W}$ chromosome heterochromatin is also suggested by $\mathrm{CMA}_{3}$-staining because these regions show less fluorescence than the remainder of the chromosome (Fig. 2f).

Individual specimens show one to two, one to four and one to five Ag-NORs per cell (Fig. 3a). Similar numbers of nucleoli were observed on Ag-stained nuclei (Table 1). Five nucleoli were not observed in animal UR121, the only specimen with five Ag-NORs, possibly because of the highest number of NOR associations shown by this specimen, 22 out of the total 38 NOR associations observed. NORs are located on

Table 1 Summary of cytogenetic observations

\begin{tabular}{|c|c|c|c|c|c|c|c|c|c|c|c|c|c|c|c|c|}
\hline \multirow[b]{2}{*}{ Animal } & \multirow[b]{2}{*}{ Sex } & \multicolumn{6}{|c|}{ Metaphases examined } & \multirow{2}{*}{$\begin{array}{l}\text { Total number } \\
\text { of } \mathrm{Ag} \text {-NOR } \\
\text { chromosomes }\end{array}$} & \multicolumn{3}{|c|}{$\begin{array}{l}\text { Ag-NORs } \\
\text { location }\end{array}$} & \multirow{2}{*}{$\begin{array}{l}\text { Ag- } \\
\text { stained } \\
\text { nuclei }\end{array}$} & \multicolumn{4}{|c|}{$\begin{array}{l}\text { Ag-stained } \\
\text { nucleoli }\end{array}$} \\
\hline & & Total & C-bands & DAPI & $\mathrm{Q}$ & $\mathrm{CMA}_{3}$ & $\mathrm{Ag}$ & & A & B & $\mathrm{C}$ & & 1 & 2 & 3 & 4 \\
\hline UR61 & $F$ & 147 & 27 & 30 & - & 12 & 35 & 51 & 51 & 0 & 0 & 69 & 45 & 21 & 3 & 0 \\
\hline UR85 & $\mathrm{F}$ & 152 & 13 & 20 & 10 & 32 & 42 & 147 & 79 & 0 & 68 & 26 & 3 & 17 & 5 & 1 \\
\hline UR116 & $\mathrm{F}$ & 212 & 33 & 34 & 25 & 34 & 107 & 360 & 199 & 0 & 161 & 85 & 43 & 31 & 5 & 6 \\
\hline UR121 & $\mathrm{F}$ & 96 & 33 & 16 & - & 24 & 45 & 168 & 85 & 73 & 10 & 72 & 10 & 35 & 12 & 15 \\
\hline UR145 & M & 63 & 21 & 21 & - & 18 & 30 & 57 & 0 & 29 & 28 & 77 & 32 & 45 & 0 & 0 \\
\hline Total & & 670 & 127 & 121 & 35 & 120 & 259 & 822 & 414 & 102 & 267 & 405 & 170 & 183 & 30 & 22 \\
\hline
\end{tabular}

$\mathrm{Q}=$ quinacrine.

$\mathrm{A}=$ Short arms of chromosomes $4 ; \mathrm{B}=$ Short arms of chromosomes $14 ; \mathrm{C}=$ Short arms of chromosomes 20.

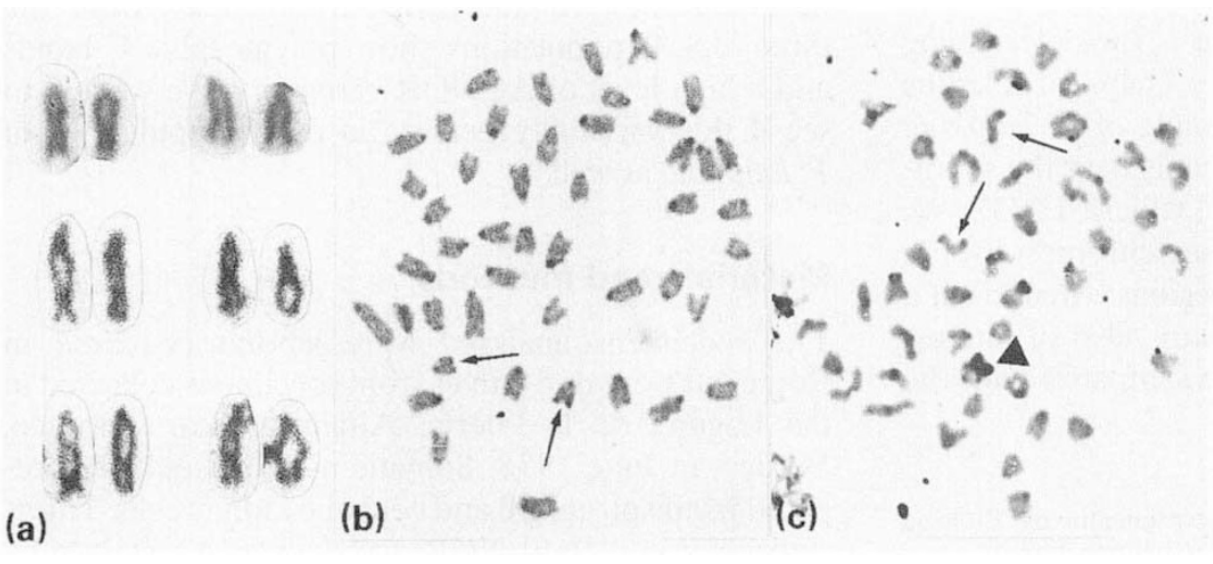

Fig. 1 (a) Partial Giemsa-stained karyotypes of P. latipinna females showing chromosome pair number 1 and the heteromorphic pair $2 ;(\mathrm{b}-\mathrm{c}) \mathrm{C}$-banded metaphase from a male (b) and female (c) specimen. The arrowhead indicates the $\mathrm{W}$ chromosome. Arrows indicate chromosomes with telomeric heterochromatin. 

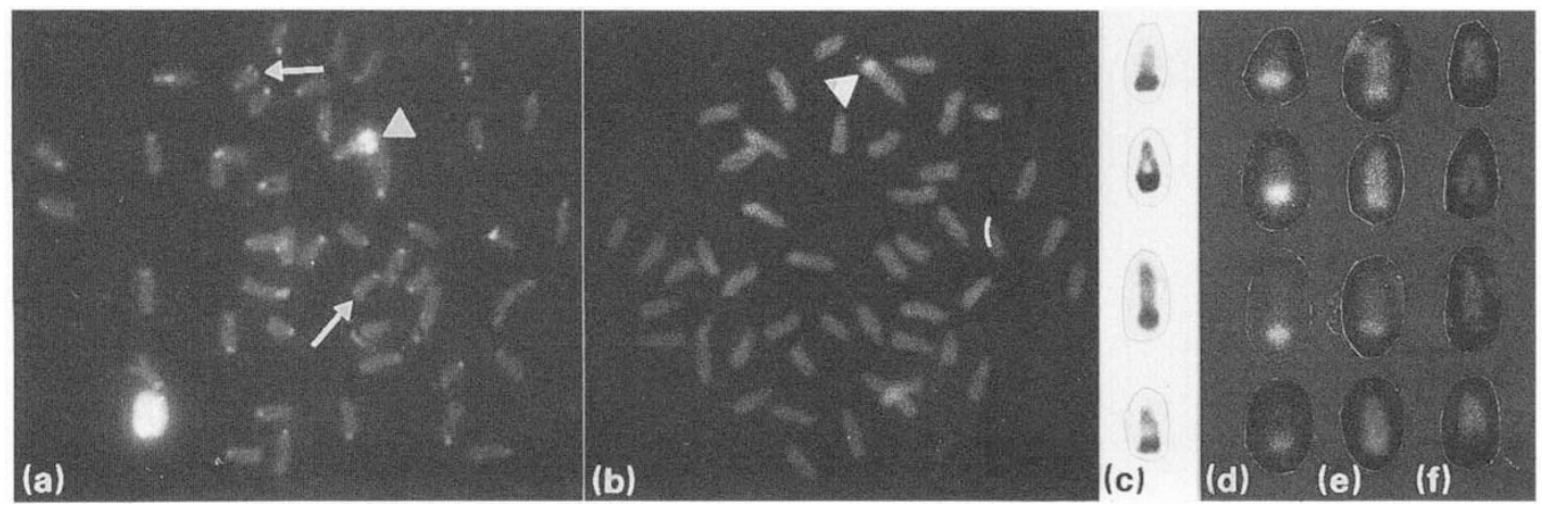

Fig. 2 (a-b) DAPI staining of previously C-banded (a) or untreated (b) metaphases from female specimens. Arrowheads indicate the $\mathrm{W}$ chromosome. Arrows in (a) indicate chromosomes with telomeric heterochromatin, DAPI-negative in the untreated metaphase (b). (c-f) Selected examples of the W chromosome after C-banding (c), after sequential C-banding and DAPI staining (d), after quinacrine staining (e) and after $\mathrm{CMA}_{3}$ staining (f). In (c) (d) and (f) the sequential staining of the same W chromosome is shown for all rows except the first one.

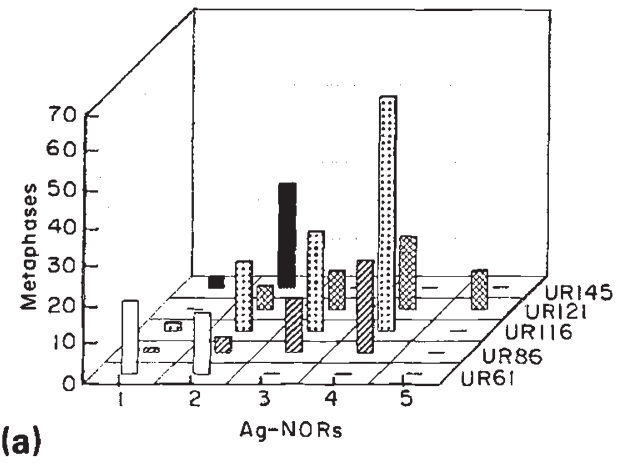

(b)

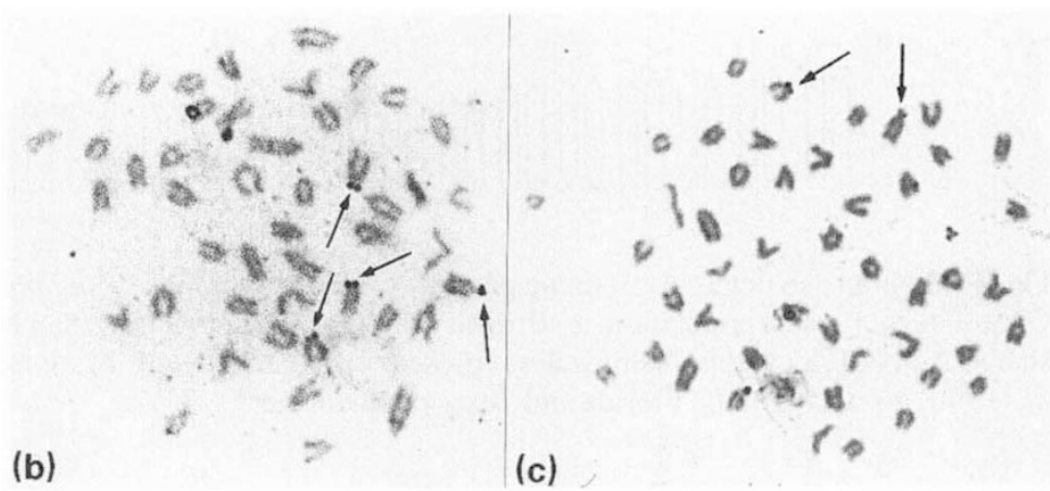

(c)

Fig. 3 (a) Distribution of Ag-stained NOR-bearing chromosomes per specimen; (b-c) Ag-stained metaphase plates. Arrows indicate Ag-NORs.

the short arms of several chromosomes (Fig. 3b and c), which for their size were numbered as chromosomes 4 , 14 and 20 (Fig. 4a). The Ag-NOR chromosomal loci found in all populations of $P$. latipinna surveyed to date, are represented as small circles on the idiograms shown in Fig. 4. Chromosomal loci that were found to have an Ag-positive NOR in at least one cell from every specimen belonging to a population are indicated as solid circles, while those loci showing $\mathrm{Ag}$-positive NORs in cells from only some specimens of a population are indicated as open circles. To minimize the arbitrariness of classification, chromosomes of similar size showing NORs on the same location were considered as homologues.

\section{Discussion}

Observations presented here on the Tampico population of P. latipinna, coupled with our previous observa- tions in this species (Sola et al., 1990), indicate that the $\mathrm{ZW} / \mathrm{ZZ}$ chromosomal mechanism of sex determination is common within individuals sampled from a broad geographical range. $\mathrm{W}$ chromosome differentiation in this species has been found to be related to the accumulation of AT-rich repetitive DNA. A similar accumulation of AT-rich DNA has been described for the W chromosome of $P$. sphenops var. melanistica (Haaf \& Schmid, 1984). Thus species in the genus Poecilia, which underwent sex chromosome differentiation toward female heterogamety, seem to share a similar history with respect to cytological differentiation, or a common ancestral species. Contrary to this latter hypothesis, $P$. mexicana, considered part of the $P$. sphenops species complex (Miller, 1983), does not show morphologically differentiated sex chromosomes (Sola et al., 1992b). Moreover, it remains peculiar that congeneric species do not share the same type of sex chromosome heterogamety. For example, males of $P$. 
(a)

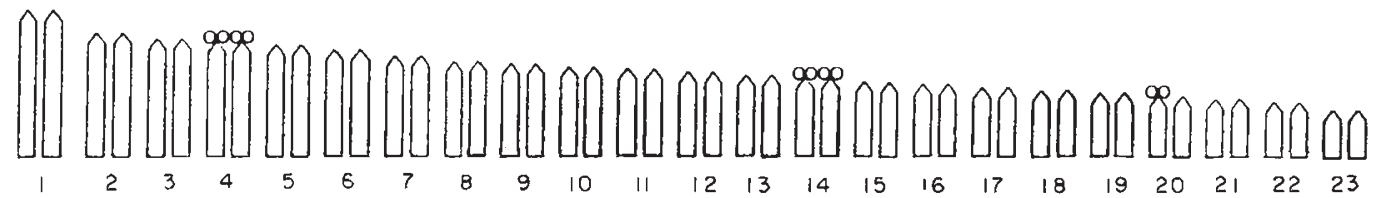

(b)

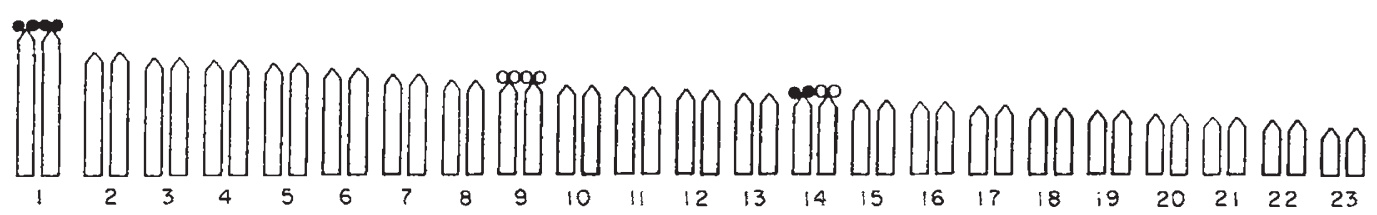

(c)

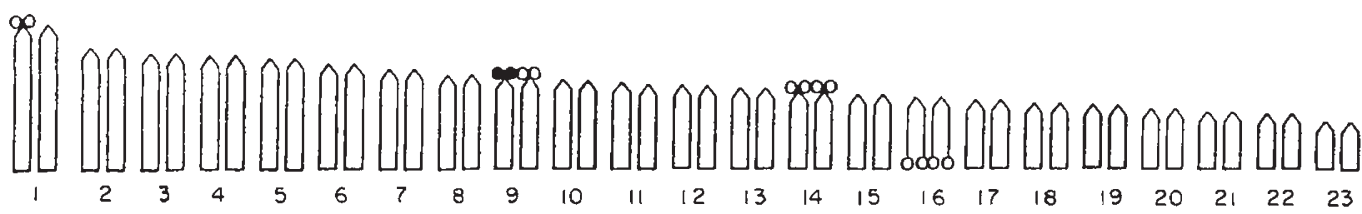

(d)

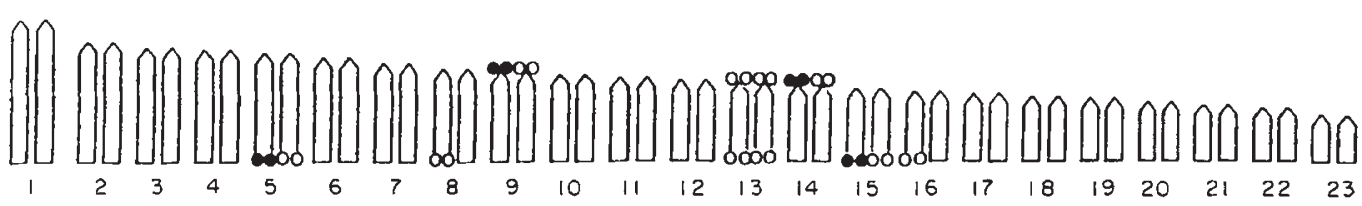

Fig. 4 Idiograms to detect Ag-staining patterns in all populations of P. latipinna surveyed to date. (a) Tampico population; (b) Gator Creek, Florida population; (c) Brownsville, Texas population; (d) San Marcos, Texas population. Solid circles represent shared Ag-NOR locations, open circles represent variable Ag-NOR locations. See text for further explanation. Refer to Sola et al. (1990) for details of the Florida and Texas populations.

reticulata appear to show XY heterogamety (Nanda et al. 1990, 1992).

Specimens of $P$. latipinna sampled from Tampico show one pair of small chromosomes with telomeric heterochromatin. Thus their C-banding pattern is similar to that shown by Florida specimens (Sola et al., 1990), by melanistic P. sphenops (Haaf \& Schmid, 1984) and by P. m mexicana (Sola et al., 1992b). This pattern has been proposed to be typical for the genus (Sola et al., 1990). However, the telomeric bands of this chromosome pair in P. latipinna do not seem to be ATrich as reported for $P$. sphenops (Haaf \& Schmid, 1984). We find these bands to be fluorescent only after DAPI staining of C-banded metaphases, and not after DAPI or quinacrine staining of untreated slides. The former condition non-specifically enhances contrast between euchromatin and heterochromatin (Sola et al., 1992b).

Numbers of NORs per cell in the Tampico specimens of $P$. latipinna were comparable to those observed in the population sampled from Florida. However, NORs on the short arms of chromosome 1, common to the Florida population, or telomeric
NORs, common to the Texas populations, were not observed in the specimens derived from the Tampico population. Additional NOR locations were found on short arms of chromosome pairs number 4 and 20, even if both homologues of the latter pair were never simultaneously Ag-stained. The data on Tampico specimens suggest that intraspecific polymorphism of $\mathrm{Ag}-\mathrm{NORs}$ is more widespread than previously suspected (Sola et al., 1990). Studies with $\mathrm{CMA}_{3}$-staining, which should yield information on structural NORs, are presently underway. However, data discussed above already indicate that while some NOR loci appear to be differentially distributed among widely disparate populations, variable distributions of NORs among specimens from the same population are also possible.

\section{References}

BALSANO, J. S., RASCH, E. M. AND MONACO, P. J. 1989. The evolutionary ecology of Poecilia formosa and its triploid associate. In: Meffe, G. K. and Snelson, F. F. (eds) Ecology 
and Evolution of Livebearing Fishes, Prentice Hall, Englewood Cliffs, New York, pp. 277-298.

HAAF, T. AND SCHMID, M. 1984. An early stage of ZW/ZZ sex chromosome differentiation in Poecilia sphenops var. melanistica (Poeciliidae, Cyprinodontiformes). Chromosoma, 89, 37-41.

HITOTSUMACHI, S., SASAKI, M. AND OJIMA, Y. 1969. A comparative karyotype study in several species of Japanese loaches (Pisces, Cobitidae). Jpn. J. Genet., 4, 157-161.

HOWELL, W. M. AND BLACK, D. A. 1980. Controlled silver-staining of nucleolus organizer regions with a protective colloidal developer: a 1-step method. Experientia, 36, 1014-1015.

KALLMAN, K. D. 1984. A new look at sex determination in Poeciliid fishes. In: Turner, B. J. (ed.) Evolutionary Genetics of Fishes, Plenum Publishing, Co., New York, pp. 95-171.

MILLER, R. R. 1983. Checklist and key to the mollies of Mexico (Pisces: Poeciliidae: Poecilia, Subgenus Mollienesia). Copeia, 1983, 817-822.

NANDA, I., FEICHTINGER, W., SCHMID, M., SCHRODER, J. H., ZISCHLER, H. AND EPPLEN, J. T. 1990. Simple repetitive sequences are associated with differentiation of sex chromosomes in the guppy fish. J. Mol. Evol., 30, 456-462.
NANDA, l., SCHARTL, M., FEICHTINGER, W., EPPLEN, J. T. AND SCHMID, M. 1992. Early stages of sex chromosome differentiation in fish as analysed by simple repetitive DNA sequences. Chromosoma, 101, 301-310.

SOLA, L., IASELLI, V., ROSSI, A. R., RASCH, E. M., AND MONACO, P. J. 1992a. Cytogenetics of bisexual/unisexual species of Poecilia. III. The karytype of Poecilia formosa, a gynogenetic species of hybird origin. Cytogenet. Cell Genet., 60, 236-240.

SOLA, L., MONACO, P. J. AND RASCH, E. M. 1990. Cytogenetics of bisexual/unisexual species of Poecilia. I. C-bands, AgNOR polymorphism and sex chromosomes in three populations of P. latipinna. Cytogenet. Cell Genet., 53, $148-154$

SOLA, L., ROSSI, A. R., IASELLI, V., RASCH, E. M. AND MONACO, P. J. 1992b. Cytogenetics of bisexual/unisexual species of Poecilia. II. Analysis of heterochromatin and nucleolar organizer regions in Poecilia mexicana mexicana by C-banding, DAPI, Chromamycin $\mathrm{A}_{3}$ and Ag-staining Cytogenet. Cell Genet., 60, 229-235.

SUMNER, A. T. 1972. A simple technique for demonstrating centromeric heterochromatin. Exp. Cell Res., 75, 304-306. 